\title{
O TRABALHO DA EQUIPE MULTIDISCIPLINAR DA ASSISTÊNCIA ESTUDANTIL NO IFCE - CAMPUS FORTALEZA/CE
}

\author{
Helena de Lima Marinho Rodrigues Araújo70 \\ Francisca Rejane Bezerra Andrade ${ }^{71}$
}

\section{RESUMO}

Este artigo é parte do Relatório de Pós-Doutorado realizado na Universidade Estadual do Ceará (UECE) ${ }^{72}$, finalizado em agosto de 2016. O objetivo desse estudo foi compreender aspectos sobre o trabalho da equipe multidisciplinar da Assistência Estudantil do Instituto de Educação, Ciência e Tecnologia do Ceará (IFCE) - campus Fortaleza. É um estudo qualitativo e foram utilizados o depoimento de membros da gestão, bem como as entrevistas semiestruturadas com a assistente social, a pedagoga e a psicóloga. Os resultados sinalizaram que a ausência de uma Controladoria de Assistência Estudantil, falta de integração da equipe, quadro restrito de funcionários e orçamento insuficiente dificultam o trabalho da equipe multidisciplinar.

Palavras-chave: Assistência Estudantil. Equipe Multidisciplinar. IFCE.

\begin{abstract}
70 Profa. Doutora em Educação. Programa de Pós-graduação em Educação da Universidade Estadual do Ceará - UECE. Membro do Grupo de Estudos em Políticas Públicas e Exclusão Social (GEPPES). Membro do Observatório Juventude, Educação Profissional e Trabalho (JEPTRA).E-mail: helenamarinho@virtual.ufc.br.
\end{abstract}

71 Profa. do Mestrado Acadêmico em Serviço Social, Programa de Pós-Graduação em Educação da UECE, Curso de Serviço Social da Universidade Estadual do Ceará - UECE. Líder do Grupo de Estudos em Políticas Públicas e Exclusão Social (GEPPES). Coordenadora do Observatório Juventude, Educação Profissional e Trabalho (JEPTRA). E-mail: rejanemarkert@yahoo.com.br.

72 "Educação superior, assistência estudantil e atuação docente: do direito social à efetivação de uma política pública no Instituto de Educação, Ciência e Tecnologia do Ceará- campus Fortaleza" se constituiu como um Projeto Piloto para alicerçar a pesquisa em conclusão desenvolvida pelo Grupo de Estudos e Pesquisas em Políticas Públicas e Exclusão Social (GEPPES), coordenado pela profa. Dra. Francisca Rejane Bezerra Andrade (também supervisora do estágio Pós-Doutoral), abrange os Institutos de Educação, Ciência e Tecnologia do Ceará (IFCE) de Canindé, Crateús, Maracanaú, Limoeiro do Norte, Juazeiro do Norte e Fortaleza. Teve como objetivo geral analisar as potencialidades e limites do processo de democratização do Ensino Superior para o êxito dos estudantes dos cursos de graduação do IFCE - campus Fortaleza, contemplados com a assistência estudantil, no seu acesso e permanência no mercado de trabalho cearense, considerando ainda a ação docente nesse processo. 


\title{
THE WORK OF THE MULTIDISCIPLINARY TEAM STUDENT ASSISTANCE \\ IN THE IFCE - CAMPUS FORTALEZA / CE
}

\begin{abstract}
This article is part of the Post-Doctorate Report held at the State University of Ceará (UECE), finalized in August 2016. The objective of this study was to understand aspects about the work of the multidisciplinary team of Student Assistance of the Ceará Institute of Education, Science and Technology (Fortaleza). It is a qualitative study and the testimony was used as well as semi-structured interviews with the social worker, the pedagogue and the psychologist. The results signaled that the absence of a Controling Student Assistence, lack of team integration, limited staff and insufficiente budget difficult the work of the multidisciplinary team.
\end{abstract}

Keywords: Student Assistance. Multidisciplinary Team. IFCE.

\section{EL TRABAJO DEL EQUIPO MULTIDISCIPLINARIO DE ASISTENCIA DEL ESTUDIANTE EN EL CAMPUS IFCE FORTALEZA/CE}

\section{RESUMO}

Este artículo es parte del Informe de Postdoctorado realizado en la Universidade Estadual do Ceará (UECE), finalizado en agosto de 2016. El objetivo fue comprender aspectossobre el trabajo del equipo multidisciplinar de la oficina de Asistencia Estudiantil del Instituto de Educación, Ciencia y Tecnología de Ceará (IFCE) campus de Fortaleza. Es un estudio de tipo cualitativo y utiliza el testimonio de miembros de la dirección, también como entrevistas semiestructuradas con la trabajadora social, educadores y la psicóloga. Los resultados señalaron que la ausencia de una Controladoria de Assistência Estudantil, falta de integración del equipo, personal y presupuesto insuficiente dificultan el trabajo del equipo multidisciplinario.

Palavras-chave: Assistência Estudantil. Equipe Multidisciplinar. IFCE.

\section{INTRODUÇÃO}

Neste estudo teve-se como objetivo compreender aspectos sobre o trabalho da equipe multidisciplinar da Assistência Estudantil do Instituto de Educação, Ciência e Tecnologia do Ceará (IFCE) - campus Fortaleza. Nessa instituição, diferente de outros institutos cearenses, não tem uma Controladoria de Assistência Estudantil que permita a integração de todos os profissionais em um só espaço, dificultando o funcionamento do trabalho da 
equipe. Dessa forma, como esse trabalho é desenvolvido pela equipe multidisciplinar, se a ausência desse setor contribui para a fragmentação das atividades cotidianas?

Esta instituição centenária que, em 2016 completou 107 anos de funcionamento, durante esse período, esteve voltada, prioritariamente, para a formação profissional, contribuindo para $\bigcirc$ desenvolvimento socioeconômico e cultural do Estado do Ceará.

Vale ressaltar o fato de essa instituição, desde 2008, como Instituto Federal, ofertar também a Educação Superior, pois antes atendia somente ao nível médio profissional, como aquele nível se destinava à formação da elite esse atendia à população que, desprovida de recursos financeiros, precisava de trabalho para sobreviver. Nesse âmbito, para que os alunos permanecessem e concluíssem seus cursos, se fazia necessário que a instituição tivesse meios de subsidiar, sobretudo, com recursos financeiros, que esses discentes lograssem êxito e finalizassem seus cursos. Esse motivo foi um fator decisivo para o limiar de planejamento, projetos e programas de auxílios que proporcionassem assistência a esses estudantes.

É um estudo qualitativo que teve como lócus o IFCE - campus Fortaleza e foram utilizados os depoimentos da coordenadora do Serviço Social, nomeada por CSS, realizado em 12 de abril de 2016 e do diretor de Extensão, denominado por DE, concretizado em 25 de abril de 2016, bem como, as entrevistas semiestruturadas realizadas em 16 de julho de 2016 com as integrantes da equipe multidisciplinar: a assistente social designada por A1, a pedagoga e a psicóloga, identificadas por P1 e P2, respectivamente.

Este estudo foi estruturado da seguinte forma - Apresentação de aspectos históricos da assistência estudantil no IFCE, Descrição dos procedimentos metodológicos, Resultados e discussão das entrevistas seguidas das Considerações finais. 


\section{ASPECTOS HISTÓRICOS SOBRE A ASSISTÊNCIA ESTUDANTIL NO IFCE}

Em consonância com o depoimento da CSS (2016), nessa instituição, sempre houve auxílios para os alunos que não podiam permanecer nos cursos por motivo de falta de recursos econômicos. O auxílio do Programa Especial de Bolsa Estudantil (PEBE) já existia desde o funcionamento da instituição e foi extinto em 1985, contando até para aposentadoria dos que recebiam esse benefício. Depois dessa data, foi criada a Bolsa Trabalho, hoje auxílio-formação; a merenda escolar sempre existiv e, atualmente, todos os alunos dessa instituição recebem a merenda.

Além desses, existiam também outros auxílios, porque a Escola, na época, arrecadava dinheiro da Caixa Escolar (oriundo das inscrições dos cursos e esse recurso só poderia ser usado para os auxílios) e com esse dinheiro a Instituição proporcionava auxílio pedagógico, alimentação, transporte, moradia e auxílio técnico, porque os meninos não tinham dinheiro para comprar as réguas de desenho, por exemplo (CSS, 2016).

Sobre a criação da Caixa Escolar no Brasil, Vasconcelos (2013, p. 56) ressalta que tem início com as escolas profissionais,

[...] que deveriam lecionar seus conteúdos e suas aplicações de acordo com as necessidades de cada província ou região do Império, voltadas para as artes e indústrias dominantes, que estavam sendo instaladas ou desenvolvidas no país, ou seja, há uma adaptação tanto temporal como local pela cultura da região, e para dar sustentação econômica às escolas profissionalizantes, como diz o próprio texto, é que foram criadas as Caixas Escolares, portanto, elas já nascem com a missão de ajudar a financiar a educação.

A Caixa Escolar de Fortaleza foi criada em 1922 com base no Regulamento de Ensino e Reforma de 1922 e tinha como objetivo proporcionar auxílios aos alunos carentes, como: merenda, livros, vestuário, calçados e cadernos. Outro objetivo era o controle da frequência e a premiação desses alunos mediante a concessão desses auxílios (VASCONCELOS, 2013). 
A instituição, em 1990, tinha ainda a denominação de Escola Técnica Federal do Ceará e a assistência estudantil era vinculada ao Departamento de Pedagogia e Apoio Didático (DPAD) e à Coordenadoria de Orientação Educacional (COE), e não havia o Departamento de Serviço Social, implementado no ano seguinte, que data da chegada dessa coordenadora à Instituição. No ano seguinte, essa coordenadora e uma equipe restrita, elaboraram o Projeto de Implantação do Serviço Social (MARTINS, DUMARESQ \& FORTES, 1991, p. 6), com os seguintes objetivos

\begin{abstract}
Atender os educandos nos seus aspectos psicossocial e econômico, favorecendo assim um aprendizado de forma integral; Ajudar os educandos a encontrar o caminho para a obtenção de suas satisfações pessoais e sociais de forma independente e Criar condições para que os alunos formem uma consciência crítica sobre a importância do seu papel profissional na transformação da sociedade.
\end{abstract}

Percebe-se nesses objetivos um cuidado com a formação integral dos discentes visando à conscientização crítica e à transformação da sociedade. Esses aspectos estão na Legislação Brasileira: Constituição Federal (BRASIL, 1988), Lei de Diretrizes e Bases da Educação Nacional - LDB n 9.394 (BRASIL, 1996) e nas teorias Histórico-Crítica e Libertadora, de Paulo Freire, que defendem uma formação política, abrangendo a autonomia e a cidadania para a transformação social.

Ainda sobre o projeto retrocitado, é importante enfatizar qual era a sistemática de operacionalização que alicerçava o serviço social proposto: Relação Escola-Família, que era a área primordial do projeto, tendo o acompanhamento sistemático das atividades desenvolvidas (observações, relatórios, reuniões e análise de documentos, encaminhamentos, entrevistas, visitas domiciliares, dentre outros) e a avaliação de todos os eventos realizados (palestras, seminários, campanhas dentre outros). Outro fator que merece destaque são as atividades que o Serviço Social deveria desenvolver junto com os demais departamentos: 
Quadro 1 - Atividades do Serviço Social no Projeto - Implementação do Serviço Social na Escola Técnica Federal do Ceará

\begin{tabular}{l} 
Executar a política de assistência estudantil e assistir os alunos carentes. \\
Executar os programas de bolsas de estudo e/ou de trabalho. \\
\hline $\begin{array}{l}\text { Promover a integração da Escola Técnica Federal do Ceará com outras } \\
\text { instituições de ensino. }\end{array}$ \\
\hline $\begin{array}{l}\text { Realizar levantamento socioeconômico relativo ao corpo discente da escola, } \\
\text { visando a uma atuação preventiva de problemas sociais a nível individual e } \\
\text { comunitário. }\end{array}$ \\
$\begin{array}{l}\text { Orientar o grêmio livre da escola e atender alunos com problemas } \\
\text { socioeconômicos e psicológicos, que interferiram no seu rendimento escolar. }\end{array}$ \\
\hline $\begin{array}{l}\text { Encaminhar às instituições especializadas os alunos que necessitam de } \\
\text { assistência. }\end{array}$ \\
\hline Atender o grupo familiar do aluno em suas dificuldades, em casos específicos. \\
\hline
\end{tabular}

Fonte: Projeto (MARTINS, DUMARESQ \& FORTES, 1991, p. 9). Elaboração própria (2016). Lembrando que a grafia desta palavra foi escrita em fonte de 1991.

Após a criação desse setor na Instituição, iniciava-se uma mudança nos modos de acompanhamento dos estudantes, fato que pode ser atribuído à formação dos profissionais na área do Serviço Social. O trabalho antes era realizado por pessoas da Instituição que não tinham a formação específica. Em 1997, o setor de Serviço Social foi vinculado à Extensão e funcionava apenas com a coordenadora e uma técnica, ambas do Serviço Social, que iniciaram uma batalha para concurso público e reconhecimento do setor.

Então eu comecei um trabalho de formiguinha e tinha poucos assistentes sociais, uma que hoje é pró-reitora de extensão e na época era Escola Técnica, [...] e agente começou a fazer um trabalho para implementação do setor porque todo o trabalho desenvolvido de assistência ao estudante era feito pelo gabinete do diretor e passou a ser feito pela equipe multidisciplinar que ainda não era coordenadoria que era a pedagoga, duas assistentes sociais e uma psicóloga. Sempre existiu psicólogo aqui não como psicólogo clínico ou escolar, mas psicólogo contratado como professor, mas atuando na equipe multidisciplinar. Essa equipe fazia todo o trabalho de assistência estudantil então a gente fazia projetos com os pais, com a comunidade e com os alunos (CSS, ABRIL, 2016) (Grifou-se).

Um ponto relevante mencionado na conversa com a CSS (2016), no tocante ao trabalho dos integrantes do setor de Serviço Social na atualidade, foi relacionado à formação do assistente social, se reportando à 
dimensão acadêmica de grupo de estudo e produção de artigos em detrimento da falta de tempo pela grande quantidade de alunos no campus, e foi apresentado como um fator impactante no funcionamento e melhor aproveitamento dos dados disponibilizados no setor:

\begin{abstract}
Agora a nossa equipe do serviço social é tão mínima que a gente não consegue sentar para estudo, escrever artigo academicamente, precisa. Quando cheguei aqui em 1991 toda sexta-feira à tarde a orientadora pedagógica e outros professores sentávamos e tínhamos - Grupo de Estudo da Educação era distribuído textos, analisados dava o parecer e elaborávamos projeto para nosso trabalho. Mas a gente não pode comparar em 1991 com 500 alunos e hoje a gente tem ensino médio, ensino técnico, ensino superior (tecnológico, licenciatura e bacharelado) e pós-graduação, então é muita coisa. Uma instituição que cresce, mas não olha a base, podemos criar mais um curso se não damos conta dos que já tem? (CSS, 2016).
\end{abstract}

Observa-se que há uma conscientização da importância da formação continuada dos profissionais, como também se percebe uma preocupação de acompanhamento da formação desses alunos e sua inserção no mercado de trabalho.

No governo de Luís Inácio Lula da Silva (2000), houve a expansão do ensino tecnológico em todo o País e foram ofertadas vagas para o setor de Serviço Social em todos os campis do IFCE. São 44 assistentes sociais - seis delas estão lotadas no Campi Fortaleza e somente duas não trabalham com a assistência estudantil e estão lotadas na Reitoria. Há campis com poucos alunos e não tem como justificar para o Ministério da Educação concurso para esse local, pois depende da demanda. Pela lei, são cerca de 500 alunos para cada assistente social. A escola foi passando para Centro Federal e depois para Instituto e hoje tem na Coordenadoria de Serviço Social: duas assistentes sociais, dois psicólogos, três estagiárias do Serviço Social - duas colaram grau e não podem mais ser estagiárias -, portanto, existe apenas uma estagiária (CSS, 2016).

Atualmente, a assistência estudantil no campus Fortaleza é vinculada à Extensão e tem como base o Decreto n 7.234, de 19 de julho de 2010, sancionado pelo presidente Lula, dispõe sobre o Programa Nacional de 
Assistência Estudantil (PNAES) (BRASIL, 2010), documento que alicerça O Regulamento da Política de Assistência Estudantil (RAE) do IFCE (2015).

Em relação à equipe multidisciplinar, segundo conversa informal com a coordenadora - CSS é composta por todos os profissionais especificados no RAE (2015, p. 4) que trata desse assunto da seguinte maneira:

Art. $7^{\circ}$ - cada campus terá equipe multidisciplinar mínima constituída por pedagogo, assistente social, psicólogo, enfermeiro e nutricionista. Parágrafo único - será considerada equipe completa, no campus, quando houver cargos preenchidos por profissionais provenientes das seguintes áreas:

I - assistente social; II - educador físico; III - enfermeiro, IV - médico, Vnutricionista, $\mathrm{VI}$ - odontólogo, VII - pedagogo, IX - assistente de aluno e X - técnico em assuntos educacionais.

De acordo com a fala dessa coordenadora - CSS, há uma peculiaridade do campus Fortaleza que é $O$ fato de não existir Coordenadoria de Assistência Estudantil, e essa equipe, embora completa, referindo-se ao Regulamento mencionado, pertence a Coordenadorias distintas:

A equipe é formada por psicólogos, assistente social, pedagogo, odontólogo, médico e enfermeiro é uma equipe completa como rege o regulamento, mas todos pertencem a uma coordenadoria e não existe um departamento de assistência estudantil (CSS, 2016).

Sobre as definições das modalidades dos auxílios, são mostrados os seguintes tipos nesse documento RAE $(2015$, p. 2,3 e 4):

I. moradia, II. alimentação, III. transporte, IV. óculos, V. Proeja73, VI. visitas/viagens técnicas, VII. acadêmico (a. de ensino, pesquisa e extensão; b. socioestudantis e c. de desporto e cultura), VIII. didáticopedagógico, IX. discentes mães/pais, X. formação e XI. Préembarque internacional.

Vale ressaltar a importância dos recursos humanos que vão analisar a documentação e os procedimentos de entrevistas desses alunos, tanto para o acesso à bolsa e, sobretudo, durante a sua permanência, pois, além de

\footnotetext{
73 Subsidia aos discentes do programa de Educação de Jovens e Adultos, sobretudo, em seus deslocamentos, durante os meses letivos" (RAE, 2015, p. 3).
} 
não se dispor de recursos que abrangem todos os que necessitam ocorrem fatos transcendentes aos alunos e que podem ocasionar desmotivação, levando-os à reprovação e até mesmo à evasão, exemplificando a greve, problemas familiares diversos, uso de drogas, perda de algum parente, dentre outros. Esse assunto foi também mencionado na conversa informal com a coordenadora - CSS:

Muita gente critica que é assistencialismo, mas vem pra cá senta e escuta a história dos alunos. Aluno que vem lá da cidade de Caridade somente com a farda, uma blusa e calça jeans a gente investiga e ver como vai dá os auxílios, ai ele aluga um quitinete com mais 3 alunos e ai ele passa 4 ou 5 anos e se promove porque já saiu aluno daqui para todo tipo de emprego bom como para universidades até para o sul do país, saindo daqui do campus Fortaleza (CSS, 2016).

Ficou evidente a importância desses auxílios para a permanência dos alunos na Instituição até o fim do curso, porque há muitos problemas em relação à permanência na Instituição e muitas vezes não há como concluir o curso pela carência socioeconômica. Esse posicionamento foi também abordado nos achados da Dissertação de Mestrado de Menezes (2012, p. 104), quando os seus três entrevistados ressaltaram sobre a contribuição do auxílio:

Primeiro porque eu pude... não ter que ter um trabalho. Coisa que para mim não teria condições nenhuma, né? Além da iniciação científica [...] não teria como eu ter outro trabalho e fazer Física.

Foi essencial... não sei como eu faria. Acho que eu teria que me virar muito mais pra manter a faculdade. Ainda mais no começo.

Ela auxiliou... o fundamental... pra tirar xerox, se tem algum projeto cultural que não dá pra fazer. Auxiliou também no estágio, na impressão de trabalho... xerox e comprar livro.

Com o intento de ilustrar alguns dados referentes aos auxílios concedidos pelo IFCE- campus Fortaleza, na sequência são mostrados dois gráficos com elementos sobre os anos de 2014 e 2015. 
Gráfico 1: Número de Auxilios Concedidos aos Discentes da Educação Superior em 2014

\section{Quantidade de Auxílios}

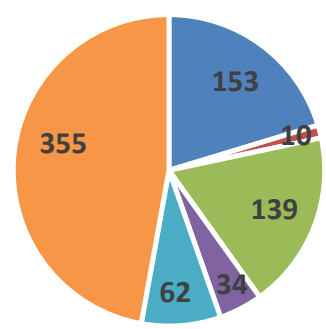

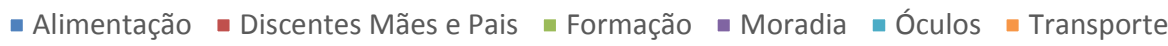

Fonte: Diretoria de Extensão - DIREX - IFCE - Campus Fortaleza. Elaboração própria (2016).

Em primeiro lugar, o auxílio-transporte foi o mais requisitado, fato que leva ao pensamento de que muitos estudantes residem fora do bairro da Instituição. A alimentação está em segundo lugar, e o que chamou atenção foi o fato de o terceiro lugar ser destinado à formação. No ano seguinte, 2015, o levantamento dos auxílios revelou os seguintes dados:

Gráfico 2: Número de Auxílios Concedidos aos Discentes da Educação Superior em 2015

\section{Quantidade de Auxílios}

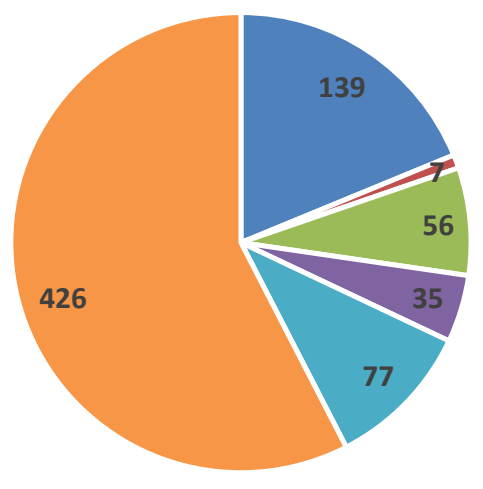

- Alimentação - Discentes Mães e Pais - Formação - Moradia - Óculos " Transporte

Fonte: Diretoria de Extensão - DIREX - IFCE - campus Fortaleza. Elaboração própria (2016). 
Realizando uma comparação nos dois gráficos, no de 2015, o auxíliotransporte continuou liderando, mas com uma diferença maior de 71 auxílios. Alimentação ficou em segundo, pois teve uma redução de 14 auxílios e, no auxílio-formação, houve uma declinação de 83 auxílios.

Sobre esse último auxílio, é importante ressaltar este fragmento da conversa informal realizada no dia 25 de abril de 2016, com o Diretor da Extensão do Campus, identificado por DE:

[...] então o IFCE trabalha agora com o auxílio formação e o aluno não trabalha ele participa dentro de um setor da instituição ligado ao ensino, algum laboratório, ligado a pesquisa ligado à formação dele por isso se chama auxílio-formação[...].Esse auxílio tem como objetivo o aluno fazer atividades de acordo com seu curso, portanto, relacionado ao processo de ensino e aprendizagem (DE, ABRIL, 2016).

Ainda sobre esse auxílio, enfatizou aspectos da atuação docente:

A atuação docente entra na orientação[...]. O coordenador e docente têm um perfil de cada laboratório de quais são as atividades a serem desenvolvidas. Os alunos serão lotados de acordo com o perfil do laboratório e do aluno levando em conta o seu curso. [...] Os docentes são os concursados de cada departamento e que estão lotados com aulas nos laboratórios. São disciplinas que exigem parte teórica e prática e que podem serem ministradas pelo mesmo professor ou em outra situação um trabalha a parte teórica e outro a prática (DE, ABRIL, 2016).

O auxílio-formação é uma maneira de articular a formação e o trabalho do estudante já na realização do curso, possibilitando mais condições para que o processo de ensino-aprendizagem se desenvolva com mais qualidade.

\section{PROCEDIMENTOS METODOLÓGICOS}

Pesquisa de abordagem qualitativa (BOGDAN; BIKLEN, 1994; MINAYO, 1994; POLAK, SANTANA, ARAÚJO, 2014) e estudo de caso, caracterizado por Yin (2001, p. 19) [...] "pela capacidade de lidar com uma completa variedade de evidências, documentos, artefatos, entrevistas e observações". 
O lócus para aplicação da entrevista semiestruturada foi O IFCE campus Fortaleza, tem a Reitoria sediada em Fortaleza, unidade criada nos termos da Lei $n^{\circ} 11.892$, de 29 de dezembro de 2008. É uma autarquia (IFCE) de natureza jurídica, detentora de autonomia administrativa, patrimonial, financeira, didático-pedagógica e disciplinar. Para efeito da incidência das disposições que regem a regulação, avaliação e supervisão institucionais e dos cursos de Educação Superior, o IFCE é equiparado às universidades federais.

Participaram da pesquisa cinco sujeitos, sendo três integrantes da equipe multidisciplinar que foram entrevistadas: a assistente social - Al, especialista em Gestão de Organizações Sociais pela Universidade Estadual Vale do Acaraú (UVA) e trabalha na Instituição desde 2009; a pedagoga - P1 - é especialista em Psicopedagogia pela UECE e iniciou suas atividades em 2010; e a psicóloga - P2- é mestra em Psicologia pela Universidade de Fortaleza (UNIFOR), e também ingressou na Instituição em 2009. As entrevistas foram efetivadas no dia 16/07/2016. Os outros dois sujeitos foram a coordenadora do Serviço Social - CSS e o diretor de Extensão - DE, ambos participaram mediante depoimentos realizados nos dias 12 e 25 de abril de 2016, respectivamente.

\section{RESULTADOS E DISCUSSÕES DAS ENTREVISTAS}

As falas desses sujeitos serão apresentadas simultaneamente, seguindo a ordem A1, P1 e P2, de acordo com os questionamentos do roteiro. $\mathrm{O}$ ato de avaliar, embora seja muito antigo, visto que é uma especificidade humana, é muito complexo e considera-se necessário não apenas o foco nos resultados, mas que possibilite a articulação da óptica qualitativa sobre a quantitativa, estabelecendo um planejamento com objetivos e metas para lograr êxito na situação evidenciada no momento, Demo (1999, p. 1) enfatiza que

Refletir é também avaliar, e avaliar é também planejar, estabelecer objetivos etc. Daí os critérios de avaliação, que condicionam seus resultados estejam sempre subordinados a finalidades e objetivos 
previamente estabelecidos para qualquer prática, seja ela educativa, social, política ou outra.

Sobre as funções da avaliação, Libâneo (1995, p. 195), ressalta [...] que cumpre funções pedagógico-didáticas, de diagnóstico e de controle em relação às quais recorre a instrumentos de verificação. Inserido no tema avaliação o questionamento inicial foi direcionado a avaliação sobre a Política de Assistência Estudantil

Existe o programa em âmbito nacional que ele traz algumas diretrizes pra nós. Na verdade, este programa foi criado para as universidades e foi meio que adaptado paras as especificidades dos institutos, pois temos alunos do nível superior, do técnico, e do nível médio integrado ao técnico. No meu ponto de vista, o programa é um pouco assistencialista. Pois há a concessão de auxílios, mas muitas vezes não temos tempo para fazer um acompanhamento de qualidade com os estudantes (A1, JULHO, 2016).

Em consonância com a fala da Al, destacam-se dois aspectos: o fato de não se ter uma política de assistência estudantil específica para os institutos trabalhando, com a adaptação da política criada para as universidades; o outro aspecto se refere à concessão de auxílios para os estudantes, porém não existe um acompanhamento de qualidade dos alunos que recebem esses auxílios, sobretudo, no campus Fortaleza. Vale lembrar a especificidade desse Campus no tocante ao seu processo histórico de expansão dos cursos e aumento do número de estudantes, por conseguinte, ocasionando uma desproporcionalidade do espaço físico e quadro de servidores. Observando a resposta a seguir a Pl diz que a política atende os estudantes no que se dispõe e assinala a necessidade de ampliação:

Eu acredito que é uma boa política, ela atende, mas ela precisa ser ampliada, ela atende no que ela dispõe, ela consegue atender o aluno, ela precisa ser ampliada, ela precisa de uma ampliação destes recursos, para atender mais gente (P1, JULHO, 2016).

A fala da P2, na sequência, ressalta o distanciamento entre teoria e prática, enfatizando as deficiências enfrentadas pela equipe e que incidem 
na qualidade do trabalho. Outro elemento ressaltado foi a ausência de integração da equipe.

Eu avalio assim... acho muito bacana, mas na parte prática ela deixa muito a desejar [...] tem uma equipe, mas não tá trabalhando de forma integrada, não tem participação nos planejamentos das ações, não sabe a questão do orçamento. Enfim, tem uma série de coisas que acabam afetando a qualidade da prestação do serviço. [...] isso acaba repercutindo, nos alunos, na educação que a gente pretende promover (P2, JULHO, 2016).

Percebe-se que a ausência de planejamento e integração, aliadas a fatores destacados, dificultam o trabalho dessas profissionais e interfere também na qualidade da educação dos discentes. O questionamento posterior buscou saber qual o entendimento pessoal do que é Assistência Estudantil. As respostas sinalizaram que

É garantir que o estudante permaneça na instituição. Mas, que não seja uma garantia de qualquer forma, apenas dando um auxílio[...]. Hoje o carro chefe da Assistência Estudantil são os auxílios, na minha compreensão deveríamos ter também um trabalho de qualidade no acompanhamento, na psicologia, um atendimento primoroso no setor de saúde, um refeitório de qualidade para os alunos, além de oferecer a merenda escolar, oferecer almoço e jantar. Então, entendo a Assistência Estudantil com esse trabalho bem maior, do que ser apenas a questão dos auxílios (A1, JULHO, 2016).

Sobre esse questionamento, a Al enfatiza que a função da Assistência Estudantil é a garantia da permanência dos alunos nas instituições, mas que não se restrinja aos auxílios, que seja mais abrangente com um trabalho de qualidade envolvendo várias atividades, concepção que vai ao encontro das falas de P1 e P2 sobre a Assistência Estudantil.

Ela começa, quando chega alguém aqui e pede uma informação na portaria ou a um desses vigias, tudo que eu presto de serviço ela é uma assistência estudantil, não só a financeira [...] na minha visão como pedagoga, ela perpassa por toda e qualquer informação, acolhimento e serviço que eu preste ao aluno (P1, JULHO, 2016).

Acho que é o que vai fundamentar as ações voltadas para a comunidade escolar (P2, JULHO, 2016). 
Com efeito, todos esses fatores destacados (A1, P1 e P2) são relevantes e devem caminhar juntos com a concessão dos auxílios para a garantia da permanência dos estudantes na instituição, mas, de acordo com as falas, ainda é um desafio para a equipe. O questionamento seguinte se reportou à percepção da atuação de cada entrevistada no trabalho com a Assistência Estudantil, isto é, como integrante da equipe multidisciplinar:

Ela poderia ser bem melhor, mais abrangente, poderíamos trabalhar de forma mais integrada, com o trabalho interdisciplinar, mas não conseguimos, [...]acabamos que temos mais contato com 0 regulamento que traz a regulação do nosso fazer com relação aos auxílios (A1, JULHO, 2016).

Nessa resposta, a Al traz novamente a ausência da integração e da interdisciplinaridade, motivo pelo qual o trabalho acaba sendo mais voltado para os documentos. Pesquisando no $\operatorname{RAE}(2015$, p. 4-5), em relação as atribuições do Serviço Social, salienta as seguintes:

\section{Quadro 2: Atribuições do Serviço Social}

\begin{tabular}{l} 
I - Incentivar a participação democrática do discente, como sujeito de direitos, no \\
espaço educacional, favorecendo o seu acesso ao Programa Nacional de \\
Assistência Estudantil (PNAES). \\
\hline II - Planejar, executar, monitorar e avaliar as ações relacionadas aos auxílios e à \\
política de assistência estudantil. \\
\hline III - Realizar pesquisas de natureza socioeconômica e familiar para caracterização \\
da população discente, contribuindo na identificação e intervenção dos fatores \\
sociais, culturais e econômicos que influenciam no processo de ensino- \\
aprendizagem, visando a permanência e o êxito dois estudantes. \\
IV- Participar de equipes multidisciplinares para a elaboração e execução de \\
programas e projetos sociais voltados a temas relevantes, como saúde, violência, \\
cultura, cidadania, direitos sociais e humanos (questão racial, de gênero, \\
orientação sexual, deficiência, políticas afirmativas, dentre outros). \\
\hline V-Elaborar relatórios, pareceres e manifestações técnicas para subsidiar decisões \\
institucionais e promover o acesso aos direitos sociais dos discentes. \\
\hline VI - Realizar parcerias e articular as instituições locais e/ou regionais, contribuindo \\
para a minimização das vulnerabilidades enfrentadas pelos alunos e famílias. \\
\hline VIl - Realizar visitas domiciliares com o objetivo de ampliar o conhecimento \\
acerca da realidade socio-familiar do discente, de forma a assisti-lo e \\
encaminhá-lo adequadamente e com qualidade. \\
\hline VIII - Orientar os discentes e seus familiares sobre os seus direitos, de modo a \\
reforçar o seu poder reivindicatório junto às instituições responsáveis pela \\
\hline
\end{tabular}


execução das políticas sociais.

IX - Promover a atuação dos estudantes em suas entidades políticorepresentativas, realizando atividades socioeducativas, estimulando o debate acerca das diversidades e da pluralidade.

X - Assessorar a gestão dos campi em relação ao orçamento da Assistência Estudantil.

Fonte: RAE (2015, p. 4 -5). Elaboração própria (2016).

Articulando essas atribuições com as falas anteriores, percebe-se que muitas das atividades, por exemplo, as que se referem aos itens II, III, IV e IX, não são realizadas no cotidiano, principalmente pela falta de tempo dos profissionais que trabalham com um quadro mínimo de funcionários para atender a uma demanda muito elevada. Por outro ângulo, de acordo com a fala da coordenadora - CSS (2016), essas atribuições se tornavam mais prováveis de se realizarem nos anos de 1991, quando se tinha uma demanda bem inferior de 500 estudantes. Atualmente, a instituição conta com mais de sete mil estudantes, além dos demais servidores que fazem parte da comunidade institucional, que aumenta o contingente de pessoas. Essa situação também comparece à na fala da $\mathrm{Pl}$ :

O papel da gente aqui é muito unitário, como você não é chamado a um planejamento de ações, você trabalha com o que é delegado pra você e quem delega não tem essa formação, essa visão pedagógica, então restringe o teu trabalho. [...] O setor é reduzido, então você tem uma sobre carga de trabalho grande e eu não só trabalho com assistência ao estudante, eu trabalho com assistência ao professor, com a assistência aos planejamentos dos cursos, com a revisão dos documentos dos cursos (P1, JULHO, 2016).

No RAE (2015, p. 5-6), as atribuições do serviço pedagógico no artigo 12 dispõe que:

[...] envolve a orientação, no que concerne ao trabalho de conscientização, aconselhamento, informação aos pais e alunos; à supervisão, no que diz respeito ao acompanhamento das atividades do ensino e da aprendizagem: à pesquisa enfocando o levantamento, o estudo e a análise de dados e demandas para o diagnóstico educacional.

As atribuições são mostradas de maneira bem abrangente e centraliza três eixos: orientação, supervisão e pesquisa. No entanto, podem ser 
especificadas em inúmeras atribuições, o que também sobrecarrega o trabalho do pedagogo, comprometendo tanto a qualidade da execução das atividades como da saúde desse servidor. A situação indicada no exemplo da Pl abaixo, complementa tanto sua fala anterior como se aproxima dos discursos expostos pelas demais entrevistadas, contribuindo para ratificar esse aspecto no cotidiano:

[...] eu tô revisando um projeto de um curso tá com mais de quinze dias, e não é todo dia que eu consigo abrir o documento para trabalhar nele, não é todo dia e assim, e isso angustia porque só quem pode assinar para mandar pra pró-reitoria, para mandar para o Conselho Superior, são os pedagogos (P1, JULHO, 2016).

É notória a discussão sobre o quadro mínimo de funcionários, para atender a demanda atual da Instituição, como um fator determinante na precariedade das atribuições dos profissionais no cotidiano, como retratado também na fala da P2:

Ela é precária... ainda mais por conta da limitação com o pessoal, nós somos só dois pra atender um universo de quase 8 mil alunos. [...]. A gente trabalha muito assim: de acordo com a demanda que surge... as vezes eu me sinto até um pouco inibida de tá... sugerindo outras ações, porque eu acredito que eu não vou conseguir dar conta da demanda que vai surgir a partir dessa provocação, então eu acabo trabalhando com um universo muito limitado de alunos diante do que a gente tem aqui e, enfim, é complicado.

No documento retrocitado $\operatorname{RAE}\left(2015\right.$, p. 5), o artigo $11^{\circ}$ rege que 0 Serviço de Psicologia apoia a promoção do processo educativo dos sujeitos que compõem a comunidade escolar, valorizando a escuta psicológica. Destaca as ações:

I - acolhimento; II - acompanhamento; III - avaliação psicológica; IV orientação de discentes e comunidade escolar; $\vee$ - assessoria e/ou participação nos projetos coletivos, buscando a interlocução dos atores protagonistas nos planejamentos e ações educacionais; VI visitas domiciliares - mapeamento da rede de apoio e reflexão sobre os aspectos institucionais. 
Comparando a fala da P1 e as atribuições do Serviço de Psicologia, observa-se também um distanciamento em relação ao desenvolvimento de ações no cotidiano. De tal modo, chama atenção para as atribuições $V$ e VI que ficam à margem por conta dos fatores elencados que impossibilitam a realização de todas as atribuições, enfatizando também a qualidade dos serviços, assunto que antecipa uma preleção para o questionamento seguinte: quais os principais desafios enfrentados na sua atuação dentro da Assistência Estudantil?

Meu desafio hoje não seria nem dentro da Assistência Estudantil, seria dentro do serviço social [...] o nosso maior desafio é fazer com que o serviço social seja visto não só como o local onde o estudante consiga o auxílio, mas que possamos ter uma atuação para além do repasse de recurso financeiro desenvolvendo outras atividades, por exemplo, no âmbito da pesquisa, realizando trabalho em grupo com os estudantes, desenvolvimento projetos que sejam voltados para os alunos, que faça com que o trabalho do assistente social não seja apenas destinado para seleção de auxílios (A1, 2016).

A fala da Al ressalta a necessidade de fazer com que o Serviço Social seja visto como abrangente e que não se restrinja apenas ao trabalho de seleção para os auxílios. É oportuno complementar com o fragmento a seguir:

\begin{abstract}
O que temos desenvolvido são projetos pensados por outras pessoas que muitas vezes não tem relação com a Assistência Estudantil. Na verdade, necessitamos de uma equipe e um espaço maior, assim como também o compromisso coletivo da equipe para tentarmos ampliar o atendimento e a nossa prática profissional. Pois devido à grande demanda de alunos que solicitam auxílio, não conseguimos realizar outros trabalhos, desenvolver projetos e ações que estejam para além dos auxílios e acabamos apenas executando o trabalho que o orçamento nos permite. Temos seis assistentes sociais para 0 dia inteiro, das 7 h às $19 \mathrm{~h}$ (Al, JULHO, 2016).
\end{abstract}

Traz à tona dados já mencionados, que reforçam a urgência de mudanças para a aproximação da teoria e prática, isto é, documentos e fazer diário. Sobre esse mesmo questionamento, a Pl salientou como desafios na atuação: 
É a questão dos setores não terem uma visão muito clara do trabalho do pedagogo, é um trabalho que a gente faz de forma constante, mas que o pessoal olha e diz que o pedagogo não faz nada, ainda tem muito. Eles não percebem os resultados, se você não fizer algo de impacto, que você chame para segregar mais gente esse resultado não é perceptível, é como o trabalho das meninas aqui do serviço social, que o pessoal diz que só trabalha na época dos auxílios, elas trabalham monitorando esses alunos o semestre todo, chamando, reunindo-se, não é um trabalho pontuado é como o pessoal da coordenação pedagógica, a gente tem um trabalho, ali que é contínuo, mas que não é percebido ( $\mathrm{Pl}$, JULHO, 2016).

Um elemento destacado se refere à visibilidade dos trabalhos realizados. Ela ressalta que os demais setores só focam no que é perceptível para eles. No caso do Serviço Social, resume-se ao trabalho com os auxílios, assim como não percebem o monitoramento do acompanhamento dos alunos, também pelo Setor de Pedagogia. Pode-se cogitar em que a ausência das atividades que precisam de socialização, como pesquisa, minicurso, seminários, dentre outras, e que não são realizadas pelas dificuldades (falta de profissionais, de espaço físico, de integração da equipe) talvez colabore com essa impressão de que os servidores dos demais setores têm de não se ter um trabalho contínuo como enfatizado na fala da P1.

É relevante frisar o trabalho da equipe no início do semestre com os alunos novatos para apresentação e esclarecimentos sobre a assistência estudantil. Nesse momento, como se faz uma convocação é um exemplo de trabalho de impacto, levando em consideração a visibilidade. A resposta da P2 salienta três pontos, já mencionados: número reduzido de funcionários, falta de uma coordenadoria de assistência estudantil e orçamento limitado:

Número reduzido de profissionais pra um universo muito grande de alunos. A gente tem algumas ações interdisciplinares, com o serviço social com a CTP, mas são coisas pontuais, não estão sistematizadas. Eu acho que falta ter essa Coordenadoria de Assistência Estudantil aqui no campus pra integrar mais essas ações. O limite orçamentário é outra coisa que emperra. A gente deixa de adquirir materiais, jogos, testes psicológicos por essa limitação de orçamento. Eu acho que são as principais os principais desafios. (P2, JULHO, 2016). 
Em outra etapa de sua fala pontuou dois elementos que se constituem também um desafio no Campus, a heterogeneidade do público atendido na Instituição o que ela chamou de "choque de gerações" a forma de participação dos pais na intervenção junto aos seus filhos, quando transfere a responsabilidade para o profissional, como enfatizado ao final da fala seguinte:

O tratamento com o adolescente é de um jeito, com o adulto é de outro tem que ser, claro! A gente tem que reconhecer as diferenças, mas tem certas coisas que não dá, você ter que pegar o menino, ir lá, ler, preencher o formulário com ele e aí vem a mãe, o pai e querem que você pegue o menino pela mão e dê um jeito (P2, JULHO, 2016).

Essa concepção dos pais presente nessa fala leva a pensar que eles tenham uma ideia fragmentada sobre educação de seus filhos, como salientam Duru-Bellat e Van Zanten (1992, p.168 APUD OLIVEIRA, 2010, p.14): "a norma escola, é escola, casa, é casa". Assim, a Instituição e a Família têm papéis bem distintos, percepção que pode ensejar dissabores e até conflitos no relacionamento entre os discentes, profissionais e pais.

No questionamento a seguir: considera que a Assistência Estudantil contribui para a redução dos índices de retenção e evasão escolar? Se sim, como? Se não, por quê?

Não existe dados que comprove que uma das causas da evasão seja a não concessão do auxílio. Para mim nunca chegou casos que a falta de auxílio tenha ocasionado a evasão (A1, JULHO, 2016).

Caso não tivesse a assistência estudantil, o quadro seria bem pior, principalmente para aquele aluno carente, porque não é barato você estudar em uma instituição, mesmo ela sendo pública, [...]você precisa de xerox, de ônibus, a gente aqui não tem o restaurante universitário, precisa de um auxílio para ter um almoço principalmente aquele aluno que tá manhã e tarde e as vezes até noite aqui dentro assistindo aula. (P1, JULHO, 2016).

Em consonância com a fala da $\mathrm{Al}$, a falta de auxílio não é a causa para evasão, ao passo que a Pl chama atenção para a importância do auxílio financeiro na vida do estudante, mas não menciona a evasão. 
A fala a seguir traz alguns elementos que podem complementar a relação auxílio e redução da evasão

Com relação a evasão, eu acho que os auxilios ajudam muito. No entanto, tem uma série também de críticas a respeito... eles as vezes são depositados quando o semestre já tá pra encerrar. Tem atrasos... as vezes os alunos acabam usando para outros fins, porque no final das contas, como sai com muito atraso, acaba servindo pra outras coisas que não a garantia desse acesso aqui. Tem aluno que recebe auxílio transporte e reprova por falta [...]. Os alunos, por exemplo, as vezes procuram a psicologia por conta dessa não identificação do curso (P2, JULHO, 2016).

Observa-se, na perspectiva de P2, que os auxílios ajudam muito aos discentes, porém existem alguns problemas que eles enfrentam em relação ao recebimento (atraso, uso do auxílio para outros fins). Especificamente sobre a evasão, ela pontua duas situações que podem contribuir: a reprovação por falta e o descontentamento do discente em relação ao seu curso. Portanto, sua concepção vem ao encontro do que enalteceram Al e P1 de que não há uma constatação direta da relação auxílio e evasão.

Sobre a evasão, Barlem et al (2012, p.133), discute o tema e descreve alguns fatores que podem contribuir para que o estudante desista de um curso em nível superior

Diversos são os motivos que podem levar o estudante a evadir-se de um curso, os quais podem estar relacionados ao próprio universo discente, tais como imaturidade, desconhecimento ou insuficiência de informações sobre o curso em que ingressou, dificuldade de adaptação ao meio acadêmico, problemas financeiros, familiares ou, ainda, insatisfação com o sistema de ensino ou, até mesmo, descontentamento com a profissão escolhida.

São fatores que se aproximam das falas das entrevistadas quando mencionam o ponto de vista dos alunos. Na sequência, foi inquirido quais são as ações que podem ser desenvolvidas no intuito de propiciar a permanência dos estudantes até a conclusão do curso.

Além dos auxilios, eu acho que os estudantes poderiam estar mais presente na decisão de locações de recursos para os auxilios que são mais importantes para eles, [...] talvez, se fosse realizado este 
trabalho o auxílio seria mais importante do que ele é hoje. (A), JULHO, 2016).

Al destaca a participação dos discentes na decisão de locar os recursos, a instalação do refeitório, afinidade com o curso e os auxílios. Na concepção de Pl:

Acho que a gente tem é que estender as ações que a gente já tem e implantar outras de acompanhamento mesmo individual de alunos.

A gente tem umas ações da CAEF- Coordenação de apoio de educação física, que ajuda a manter o aluno aqui, as ações esportivas, as ações do pessoal de artes também, as escolas de música, dança teatro, porque pra participar das ações eles têm que tá matriculado nos cursos (P1, JULHO, 2016).

Pl salienta o acompanhamento dos estudantes e ações ligadas ao esporte, às artes, música e ao teatro, ressaltando que elas já existem e que o discente precisa estar matriculado para usufruir dessas atividades. Na perspectiva de P2:

[...] uma coisa que a gente não faz aqui que eu acho que deveríamos fazer é esse acompanhamento do aluno para se formar no tempo certo. Têm alunos que tão aqui há mais de 10 anos. [...] Tem casos e casos também (tem gente que tá com algum problema de saúde, tem os transtornos psíquicos, psicose) enfim, mas tem outros casos que não, a pessoa vai só levando com a barriga, faz só uma disciplina, às vezes justamente pra não perder o auxílio (P2, JULHO, 2016).

O discurso de P2, além de mencionar também a ação de acompanhamento do discente, faz uma correlação entre essa ação e o tempo do estudante no curso, apontando que existem alunos com muito tempo a mais que o de seu curso. Por conseguinte, deveria haver um acompanhamento contínuo no tempo certo de duração do curso.

Na pergunta seguinte, buscou-se saber como percebe que a Assistência Estudantil é compreendida pelos servidores ttécnicos administrativos e docentes). A resposta da Al sinaliza várias situações de como a Assistência Estudantil é percebida por segmentos diversos: 
É vista pelos servidores apenas como distribuição de auxilios, e pelos docentes também, em alguns casos os que são coordenadores de laboratórios procuram o serviço social para selecionar o aluno para ser bolsista naquele laboratório, neste caso é o auxílio-formação. Para alguns funcionários o serviço social é o repassador de auxílio; para o serviço médico, se algum aluno passa mal no campus, o serviço social deve entrar em contato com a família do aluno, quem tem que acompanhar o aluno ao posto, ou ao hospital na ambulância do SAMU é o assistente social; o aluno fez uso de alguma substância ou de drogas e está no Campus, leva para o serviço social. Acredito que o serviço médico não se veja como parte da Assistência Estudantil, assim como o pessoal da Coordenação Técnica Pedagógica (CTP). Embora, quando temos casos que precisam ser trabalhados por todos os profissionais conseguimos nos reunirmos (Al, JULHO, 2016).

A resposta da Pl também direciona para uma visão limitada dos demais servidores da instituição,

Bolsa, auxílio e eles nem se tocam que o trabalho que a gente faz na coordenação pedagógica é de assistência estudantil. Pensa que é só bolsa, ou então serviço da psicologia, quem tem uma visão mais ampla aí detecta a psicologia e detecta o serviço saúde, mas não detecta que a merenda escolar é um trabalho de assistência estudantil, que a biblioteca ela é um trabalho de assistência estudantil. Então a visão assim ainda é muito limitada (PI, JULHO, 2016).

É o mesmo norteamento da P2, como descrito a seguir, de percepção da maioria dos servidores de relacionar o trabalho da Assistência Estudantil somente aos auxílios, porém um aspecto chama atenção, ao concluir essa fala, que se refere ao docente e ao técnico, enfatizando uma prioridade daquele segmento no Campus.

Eu acho que eles não compreendem (pausa longa). [...] Eu acho também que o pessoal em relação ao serviço social vê muito a questão só dos auxílios, com relação à CTP, fica muito centrado só mesmo no aluno problemático, então assim, aquele encontro pedagógico que devia ser um momento pros professores estarem participando com mais afinco, eu acho que não percebem a importância [...]. O que importa aqui são os professores. Os outros servidores, os outros técnicos ficam preteridos (P2, JULHO, 2016).

Nas três respostas, há uma confluência de que a percepção dos servidores e discentes sobre a Assistência Estudantil está relacionada, à 
primeira vista, aos auxílios. Sobre a prioridade do docente em relação aos demais técnicos, algumas conjecturas podem ser cogitadas: existência ainda forte, em instituições de ensino, de um discurso tradicional que concebe o docente como detentor de conhecimento e que tem o dom da fala final. Outro aspecto é a validação desse saber em nível de titulação, como doutorado e pós-doutorado, que enseja um certo poder, como também na paridade na votação de escolha do reitor, por exemplo, a porcentagem de valor é desigual sendo maior peso o voto dos docentes e, por fim, acrescenta-se o equívoco nas falas de muitas pessoas de que existe o docente, o técnico etc, e muitas vezes não consideram que o docente também é servidor, igualmente aos demais; o que muda é a especificidade dos cargos e funções.

Os auxilios estudantis atuam transpondo a permanência universitária? Se sim, como?

Eu acredito que para além sim também, porque eles se formam aqui dentro e eles saem e eles buscam, outros cursos, ou uma pósgraduação, ou concurso e de qualquer forma aquele auxilio permitiu que ele ficasse aqui e concluísse o curso aqui, isso contribui pra que ele busque outros horizontes, essa formação que ele teve aqui dentro, ela é importante pra que ele busque outros horizontes lá fora, é minha visão particular, eu não posso te apontar um dado (P1, JULHO, 2016).

A Pl destaca o fator da conclusão do curso que proporcionou uma formação inicial para que o discente buscasse outras opções. Isso foi possível por conta dos auxílios recebidos, ideia também enfatizada por Al e P2. A pesquisa de Vargas (2011) contribui para essa discussão ao ressaltar que a assistência estudantil, ao subsidiar os discentes pobres a obter o diploma de graduação, colabora para que eles ingressem no mercado de trabalho e ampliem suas possibilidades de ascensão na sociedade.

No questionamento a seguir, foi inquirido como a equipe trabalha para que haja uma compreensão reflexiva dos benefícios para todos os estudantes. 
Não existe este trabalho (A1, JULHO, 2016).

A gente divulga, a gente fala e orienta. Pouco tempo atrás, a coordenação pedagógica trabalhava sozinha, a gente fazia o acolhimento, era num dia só, aí o pessoal ia e apresentava o setor ali pra todo mundo era geralzão. [...] A gente tá planejando agora seminário ... os cursos terão seus seminários, as licenciaturas, os bacharelados e os tecnólogos e isso pra os novatos, para informar (P1, JULHO, 2016).

Nas duas falas, mesmo a primeira sendo apenas a negação da existência do que foi questionado e a segunda ao enumerar algumas ações, observa-se que a fragmentação do trabalho da equipe ratifica o que já foi expressado de falta de integração e de planejamento da equipe. A resposta de P2 inicia também com uma negação,

[...] eu acho que isso não ocorre o trabalho é muito individualizado (pausa) infelizmente. [...] Na verdade, acaba sendo uma coisa (inaudível) do tipo, passa pro outro aí pergunta "como é que tá o fulano" e pronto. Você acaba também transferindo um pouco pro outro resolver o outro profissional e enfim, as ações mesmo de fato, coletivas elas são muito pequenas (P2, JULHO, 2016).

Essa percepção aproxima-se também do pensamento descrito nas duas falas anteriores, evidenciando a individualização e as ações coletivas serem pequenas e, mais uma vez, salienta a falta de planejamento e o trabalho cotidiano ser norteado pela demanda.

Infere-se, de maneira geral, que a ausência de uma coordenadoria específica para tratar da Assistência Estudantil se torna um grande ocasionador de desafios que influem prejudicialmente no trabalho da equipe multidisciplinar nessa instituição.

\section{CONSIDERAÇÕES FINAIS}

Este estudo mostrou algumas fragilidades na concessão de auxílios aos estudantes como também a importância de como esse recurso financeiro pode subsidiar gastos durante o curso. No tocante ao trabalho desenvolvido pela equipe multidisciplinar, sintetizando os achados das falas das 
entrevistadas, enalteceram os seguintes aspectos: sobre a Política de Assistência Estudantil - ela atende ao que se propõe, mas que precisa ser ampliada; outro aspecto mencionado foi a ausência ou conhecimento superficial da comunidade escolar sobre essa legislação.

Relacionados aos auxílios - ressaltaram a percepção de que a maioria das pessoas da instituição (servidores e discentes) relaciona o trabalho dos setores da assistência estudantil aos benefícios e que só é visualizado no processo de seleção para esses auxílios; a equipe faz a divulgação sobre a assistência estudantil no início dos semestres; considera que a falta de recebimento de auxílios não é causa para evasão, mas que sem eles a situação poderia ser pior: o atraso no repasse dos auxílios dificulta a vida desses alunos; os auxílios contribuem e ultrapassam a permanência universitária do aluno, pois concluindo a formação inicial ele tem mais chances de ingressar no mercado de trabalho.

Sobre as ações que contribuem para a permanência dos alunos, destacaram: os auxílios; a participação da Comunidade Escolar, principalmente, dos discentes no planejamento dos recursos financeiros; a instalação do refeitório; acompanhamento dos alunos e ações ligadas ao esporte, às artes, música e ao teatro, já existentes e que beneficiam os alunos matriculados.

Em relação ao trabalho da equipe multidisciplinar - enfatizaram o restrito quadro de funcionários que limita o tempo dos profissionais para um acompanhamento mais eficaz do aluno que recebe auxílio; falta de tempo para a interação e planejamento com outros componentes da equipe, como também, para desenvolverem outras ações relevantes (visitas domiciliares, estudo de casos e pesquisas).

Essas situações apresentadas reforçam a importância de algumas medidas emergenciais que contribuirão no desenvolvimento do trabalho mais qualitativo da equipe multidisciplinar nessa instituição, dentre elas, a criação de uma Controladoria de Assistência Estudantil que promova a integração de todos os profissionais da equipe em um só espaço e aproxime 
também as atividades, planejamento e oportunidades para um trabalho mais satisfatório.

Considera-se válida a implementação de programas criados para alicerçar a Educação Superior - evidenciando a assistência estudantil - pois diminui a preocupação do aluno com seus gastos diários no curso, contribui de alguma forma para o controle da evasão. Por outro ângulo, não resolve o problema, pois a educação deve ser garantida como um direito social desde a Educação Infantil para que os estudantes tenham mais condições não só de acesso, mas também de permanência e aprendizagem qualitativa em seu curso superior no tempo predestinado.

\section{REFERÊNCIAS}

BARLEM J.G.T et al. Opção e evasão de um curso de graduação em enfermagem: percepção de estudantes evadidos. Revista Gaúcha Enfermagem. Porto Alegre (RS) 2012. jun; 33(2):132-138. Disponível em $<$ http://www.scielo.br/pdf/rgenf/v33n2/19.pdf. Acesso em 2016.

BOGDAN, R; BIKLEN, S. Investigação qualitativa em Educação. Porto: LDA, 1994.

BRASIL. Constituição da república federativa do Brasil. 1988. Disponível em <http://www.palnalto.gov.br>. Acesso em 2016.

BRASIL. Decreto $\mathbf{n}^{\circ} \mathbf{7 . 2 3 4}$, de 19 de julho de 2010. Dispõe sobre o Programa Nacional de Assistência Estudantil - PNAES. Brasília, 2010. Disponível em <http://www.planalto.gov.br>. Acesso em 2016.

BRASIL. Lei $n^{\circ}$ 9.394/96 - Lei de Diretrizes e Bases da Educação Nacional LDB. Brasília, 1996. Disponível em <http://www.planalto.gov.br>. Acesso em 2016.

BRASIL. Lei $n^{\circ}$ 11.892, de 29 de dezembro de 2008 - Institui a Rede Federal de Educação Profissional, Científica e Tecnológica, cria os Institutos Federais de Educação, Ciência e Tecnologia, e dá outras providências. 2008. Disponível em <http://www.planalto.gov.br>. Acesso em 2016.

CSS - COORDENADORA DE SERVIÇO SOCIAL. Depoimento [abril 2016]. Entrevistadora: ARAÚJO, H, L, M. Fortaleza: IFCE, 2016.

DEMO, P. Avaliação qualitativa. Campinas (SP): Autores Associados, 1999.

LIBÂNEO, J. C. Didática. São Paulo: Cortez, 1995.

MARTINS, Ana Maria Cavalcante; DUMARESQ, Zandra Maria Ribeiro; FORTES, Marta Mazza Parentes (Org). Projeto de Implementação do Serviço Social na 
Escola Técnica Federal do Ceará (Colaboração de Maria do Carmo Pinheiro - estagiária do Serviço Social). Fortaleza: CEFET, 1991.

MENEZES, S. C. Assistência estudantil na Educação Superior pública: o programa de bolsas implementado pela Universidade Federal do Rio de Janeiro. 147 f. Dissertação de Mestrado da Universidade Católica - PUC. Rio de Janeiro, 2012.

MINAYO, C. O desafio do conhecimento. São Paulo: Hucitec,1994.

OLIVEIRA, M. C. G. L. Relação Família-Escola e participação dos pais. $148 \mathrm{f}$. Dissertação de Mestrado do Instituto Superior de Educação e Trabalho. Porto, 2010.

POLAK, Y. N. S.; SANTANA, J. R. \& ARAÚJO, H. L. M. R. Dialogando sobre metodologia científica. Fortaleza: Edições UFC, 2014.

REGULAMENTO DE ASSISTÊNCIA ESTUDANTIL/IFCE (RAE) (Campus Fortaleza/2015). Disponível em <http://www.ifce/fortaleza>. Acesso em fevereiro de 2016.

VARGAS, M. de L. F. Ensino superior, assistência estudantil e mercado de trabalho: um estudo com egressos da UFMG. Revista Avaliação, v 16, n 1 - p. 149-163, mar, 2011.

VASCONCELOS, D. A. Custeio da educação pública na era Vargas: a caixa escolar do Ceará (1930-1945). 135 f. Dissertação de Mestrado da Faculdade de Educação da Universidade Federal do Ceará. Fortaleza, 2013.

YIN, R. K. Estudo de caso: planejamento e métodos. Porto Alegre: Bookman, 2000.

Recebido em: Novembro de 2016

Aceito em: Março de 2017 